\title{
Anti-Icing Method Based on Reducing Voltage of Transmission Lines
}

\author{
Xiaoming LI ${ }^{1}$, Junjie HUANG ${ }^{1}$, Youbin $\mathrm{ZhOU}^{2}$ \\ ${ }^{1}$ School of Electrical Engineering, Wuhan University, Wuhan, China \\ ${ }^{2}$ Hubei Electric Power Testing \& Research Institute, Wuhan, China \\ Email: huangjjhwb@yahoo.com.cn
}

\begin{abstract}
The icing of transmission lines threatens the security of power system. This paper proposes a novel anti-icing method based on reducing voltage of the transmission lines. The line voltage can be reduced by regulating the ratio of the transformers which install the both ends of the transmission lines. The line current can be increased and the power loss of the transmission lines can also be increased, which means the heat generated by power loss increases and the icing process of the transmission lines can be restrained. When the icing may occur in the atrocious weather, the anti-icing transformers installed the both ends of transmission line are put into operation. The ratios of transformers are regulated to the appropriate value. The current of transmission line can be increased to the value that is a little greater than the critical current, which can realize the purpose of anti-icing. At the same time, the conditions of normal running in the load side are kept invariably, which can ensure the security of power system. This method can be applicable to a wide range. It's an effective measure to prevent the icing of the transmission lines.
\end{abstract}

Keywords: anti-icing, transformer, critical current

\section{1 引言}

架空輸電線路覆冰對電力系統的安全運行有著 很大影響, 會使輸電線路發生舞動, 因電氣距離不足 而閃絡, 甚至斷線倒塔。所以, 在惡劣天氣時, 必須 採取措施防止線路覆冰情況的出現。

防覆冰方法是在覆冰前採取各種有效技術措 施, 使各種形式的冰在導線上無法積覆。與已經覆冰 達到危險狀態再採取措施的除冰方法相比, 防範于未 然, 對系統的安全、經濟運行更為有利。目前常用的 防止架空輸電線路覆冰的方法有 [1]: (1) 在線路設計 時, 避免線路穿越易覆冰區域, 但在實際中線路往往 無法完全避開這些區域; (2) 在導線表面塗抹憎水性 材料, 但迄今為止, 還没有一種可以根本阻止冰雪形 成的塗料, 憎水性塗料只能最大限度地減小冰與導線 的結合力, 使其易於脫落; (3)增加導線電流防覆冰, 利用電流通過導線時, 電阻產生的焦耳熱使導線表面 溫度維持在 $0^{\circ} \mathrm{C}$ 以上, 即可防止導線覆冰。最簡單的 增加導線電流的方法是調節電網的潮流分佈, 使需要 防覆冰的導線上流過更大的電流, 但是這種方法的調
節電流大小有限, 而且有可能影響使其他線路, 使其 出現過電流。有文獻採用的方法是在變電所母線上裝 設足夠容量的並聯電容器或電抗器, 實現增加線路上 無功電流的目的[2]。但是, 對於變電所母線接有多條 進出線的情況, 增加的無功電流有可能流過其他的導 線, 而不流過需要防覆冰的導線, 使這一方法失效, 並有可能使其他線路過熱。

針對這一情況, 本文提出了一種輸電線路降壓運 行防覆冰的控制策略。通過調節安裝在輸電線路兩端 的防覆冰變壓器, 在確保線路以外節點電壓不越限的 前提下, 降低導線的電壓, 使流過導線的電流增加。 導線因為線損增加而發熱, 使覆冰過程得到抑制。如 果防覆冰變壓器採用有載調壓, 輪流調節線路兩側變 壓器變比, 可實現防覆冰控制過程負荷不停電。

\section{2 防覆冰變壓器調壓原理}

\section{1 系統結構}

輸電線路是否覆冰主要與氣象條件、負載大小等 因素有關係[3]。一般而言, 當負載較重時由於線路上 
流過的電流大, 使導線發熱多, 線路覆冰就不容易形 成。但是, 在惡劣的氣象條件下, 線路負載不一定大。 甚至在風雪災害較嚴重的情況下, 即使線路重負載運 行, 線路仍有覆冰的危險。在保證負載不變的情況 下, 增加線路的電流, 就可以防止覆冰。

防覆冰系統的總體結構如圖 1 所示。圖中 A、B 分別為變電站母線, 每條母線上除了有進出線之外, 還安裝有一台覆冰變壓器, 通過開關 (迸路器) 和母 線的各條線路相連。有載調壓覆冰變壓器的額定變比 為 1 , 通過調節分接頭, 可以改變線路一側的電壓大 小。正常運行的情況下, 開關 $S_{A 1} 、 S_{B 1}$ 閉合, 其餘開 關斷開, 防覆冰變壓器不工作。通過對氣象條件、線 路負載等情況的綜合分析, 如果 $\mathrm{AB}$ 之間的輸電線路 有可能覆冰時, 防覆冰變壓器應該投入。變壓器的投 入操作程式是: (1) 斷開 $\mathrm{S}_{\mathrm{A} 1} 、 \mathrm{~S}_{\mathrm{B} 1}$, 母線 $\mathrm{A} 、 \mathrm{~B}$ 間的 線路停電; (2) 調整變壓器 $\mathrm{T}_{\mathrm{A}} 、 \mathrm{~T}_{\mathrm{B}}$ 的變比到合適的 值; (3) 閉合 $\mathrm{S}_{\mathrm{A} 2} 、 \mathrm{~S}_{\mathrm{B} 2}$, 相當於把變壓器空載投入; (4) 閉合 $\mathrm{S}_{\mathrm{A} 3} 、 \mathrm{~S}_{\mathrm{B} 3}$, 輸電線路恢復供電。如採用的是有載 調壓變壓器調壓, 則可直接投入變壓器, 為避免環 流, 應把變壓器的變比設為 1 。然後通過合理的調節 方式, 使變壓器 $\mathrm{T}_{\mathrm{A}} 、 \mathrm{~T}_{\mathrm{B}}$ 的分接開關同步動作, 降低 輸電線路電壓, 增大電流。

當天氣轉好, 不需要防覆冰時, 再將防覆冰變壓 器退出。防覆冰變壓器的退出操作程式是投入操作程 的逆過程。

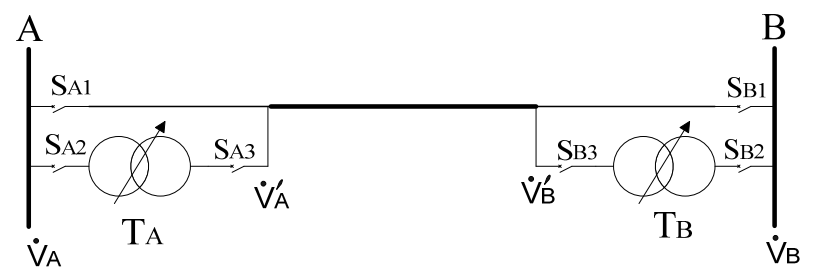

圖 1. 防覆冰系統結構圖

Figure 1. The structure of the anti-icing system

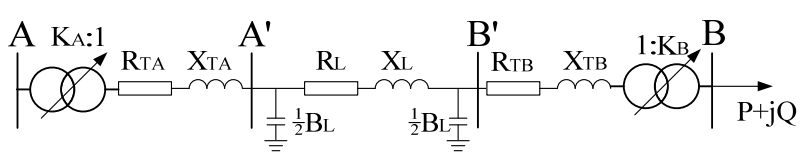

圖 2. 防覆冰系統等值電路圖

Figure 2. The equivalence circuit of the anti-icing system

\section{2 防覆冰變壓器變比}

圖 2 為防覆冰系統的等值電路圖, 其中輸電線路 用 $\pi$ 型電路等值, 變壓器用阻抗支路和理想變壓器串 聯表示。

對於防覆冰變壓器, 給出的阻抗為額定變比下的 值, 當變比為非額定時, 阻抗值會發生改變。對調壓 範圍較小的變壓器這個變化不明顯; 而本文所述變壓 器的額定變比為 1, 調壓範圍可達到 30\% 100\%的額 定電壓, 所以阻抗值的變化較大, 在等值電路中應作 修正[4]。考慮到額定變比時變壓器一二次側繞組帍數 相同，有

$$
\left\{\begin{array}{l}
R_{T}=\frac{1}{2}\left(1+k^{2}\right) R_{T N} \\
X_{T}=\frac{1}{2}\left(1+k^{2}\right) X_{T N}
\end{array}\right.
$$

其中 $\mathrm{k}$ 為變壓器實際變比, $\mathrm{R}_{\mathrm{TN}} 、 \mathrm{X}_{\mathrm{TN}}$ 為額定變比 下的變壓器電阻和電抗值。

設調壓之前, 系統由母線 A 向母線 B 傳輸功率, 母線 $\mathrm{B}$ 的輸出功率為 $\mathrm{P}+\mathrm{jQ}$, 如圖 2 所示。調壓目標 是使輸電線路的電流增加到一定值, 確保線路不覆 冰, 同時維持母線 $\mathrm{A}$ 和 $\mathrm{B}$ 的電壓不變。

圖 2 中, 母線 $\mathrm{B}$ 的電壓為 $\dot{V}_{B}$, 相連的防覆冰變 壓器變比為 $k_{B}$, 流過的電流為:

$$
\dot{I}_{T B}=\frac{P-j Q}{\widetilde{V}_{B}} k_{B}
$$

母線 $\mathrm{B}^{\prime}$ 的電壓為:

$$
\dot{V}_{B}^{\prime}=\frac{\dot{V}_{B}}{k_{B}}+\dot{I}_{T B}\left(R_{T B}+j X_{T B}\right)
$$

輸電線路上的電流為:

$$
\dot{I}_{L}=\dot{I}_{T B}+\dot{V}_{B}^{\prime} \cdot j \frac{B_{L}}{2}
$$

如果確定了線路導線不覆冰時流過的最小電 流, 即臨界電流 ILJ, 則要求 $I_{L} \geq I_{L J}$ 。由式(1) (4) 即可解出與母線 $\mathrm{B}$ 相連的變壓器變比 $k_{B}$ 的大小。 母線 $\mathrm{A}^{\prime}$ 的電壓為:

$$
\dot{V}_{A}^{\prime}=\dot{V}_{B}^{\prime}+\dot{I}_{L}\left(R_{L}+j X_{L}\right)
$$


與母線 A 相連的防覆冰變壓器流過的電流為:

$$
\dot{I}_{T A}=\dot{I}_{L}+\dot{V}_{A}^{\prime} \cdot j \frac{B_{L}}{2}
$$

母線 $\mathrm{A}$ 的電壓為:

$$
\dot{V}_{A}=k_{A}\left[\dot{V}_{A}^{\prime}+\dot{I}_{T A} \cdot\left(R_{T A}+j X_{T A}\right)\right]
$$

考慮到母線 $\mathrm{A}$ 的電壓大小在防覆冰變壓器投入前 後不變, 由式(5) (7) 可解出與母線 $\mathrm{A}$ 相連的變壓器 變比 $k_{A}$ 的大小。

要注意的是, 由於變壓器變比只能離散變化, 按 上述過程求出 $k_{A} 、 k_{B}$ 後, 應按實際變比取值。所以, 實際節點電壓在調壓前後是有變化的，應確保調壓後 節電電壓變化較小，不越限。

\section{3 運行條件校驗}

防覆冰變壓器投入後雖然保持了母線 $\mathrm{A}$ 和 $\mathrm{B}$ 的電 壓大小不變，但輸電線路首末端的電壓都減小了，而 且由於線損的增加和防覆冰變壓器的損耗, 通過線路 傳輸的功率會增加, 因此要對輸電線路傳輸功率的穩 定性進行校驗。傳輸功率極限值為:

$$
P_{\max }=\frac{V_{A}^{\prime} V_{B}^{\prime}}{X_{L}}
$$

要求線路上傳輸的有功功率應小於這個極限 值, 可以按相應的規程規定選取一定的裕度, 否則要 甩掉部分負荷保證線路的穩定性。

導線載流量的計算一般考慮的環境溫度為 $40^{\circ} \mathrm{C}$, 導線表面允許溫度為 $70^{\circ} \mathrm{C}[5]$, 而防覆冰電流要 求導線表面溫度大於 $0^{\circ} \mathrm{C}$ 即可, 遠低於 $70^{\circ} \mathrm{C}$ 。但是母 線 $\mathrm{A}$ 和 $\mathrm{B}$ 之間的輸電線路可能經過多個氣象區, 對不 需要防覆冰得區域, 過大得電流可能超過線路的熱穩 定極限，因此需要作熱穩定校驗。

允許的最大電流（即載流量）取決於環境溫度和 風速，即

$$
\begin{aligned}
& I^{2} R=9.92 \Delta t(V D)^{0.485}+ \\
& \pi \varepsilon \sigma D\left[(t+\Delta t)^{4}-t^{4}\right]-\alpha I_{s} D
\end{aligned}
$$

其中 $\Delta t$ 為導線載流時的溫升, $\mathrm{K} ; \mathrm{V}$ 為風速, $\mathrm{m} / \mathrm{s}$;
$\mathrm{D}$ 為導線外徑, $\mathrm{m} ; \mathrm{t}$ 為環境溫度, $\mathrm{K} ; \varepsilon$ 為導線表面 的輻射散熱係數, 與導線的新舊程度有關; $\sigma$ 為 Stefan-Boltzmann 常數, $5.67 \times 10^{-8} \mathrm{~W} / \mathrm{m} 2 ; \alpha$ 為導線 吸熱係數, 與導線的新舊程度有關; $I_{s}$ 為日照強度, $\mathrm{W} / \mathrm{m} 2 ; \mathrm{R}$ 為導線電阻。

\section{3 防覆冰臨界電流的確定}

臨界電流的確定，常用的方法有建立熱平衡方程 來計算 $[6][7]$ ，通過實際資料總結出經驗公式來求取 [8] 等。本文採用熱平衡方程來求解。

該方法是根據導線熱功率平衡原理求得臨界電 流。引起導線發熱的功率有：電流流過導線時產生的 熱功率, 即 $I_{L}^{2} R$; 日光對導線的日照功率, 但是由於 夜間更容易引起導線覆冰, 故從最不利因素考虑, 這 一部分不考慮。導線散熱功率有：輻射散熱功率和對 流散熱功率。如果導線溫度穩定在 $0^{\circ} \mathrm{C}$ 以上時, 發熱 功率等於散熱功率, 導線就不會覆冰。因此導線溫度 穩定在 $0^{\circ} \mathrm{C}$ 時對應的線路電流為臨界電流，即

$$
I_{L J}^{2} R=W_{R}+W_{F}
$$

其中 $\mathrm{R}$ 為導線溫度 $0^{\circ} \mathrm{C}$ 時, 單位長度的交流電 阻, $\Omega / m$, 近似用 $20^{\circ} \mathrm{C}$ 的直流電阻代替; $\mathrm{W}_{\mathrm{R}}$ 為單位長 度導線的輻射散熱功率, $W / m$; WF 為單位長度導線的 對流散熱功率, $\mathrm{W} / \mathrm{m}$ 。

$$
\begin{aligned}
& W_{R}=\pi \varepsilon \sigma D\left[273.2^{4}-t^{4}\right] \\
& W_{F}=0.57 \pi \lambda(273.2-t) R_{e}^{0.485}
\end{aligned}
$$

式中 $\lambda$ 為導線表面空氣層的傳熱係數，與環境溫 度有關； $R_{e}$ 為雷諾數，與環境溫度、風速和導線外徑 有關。

參考文獻[6]在熱功率平衡方程的基礎上, 考慮了 導線表面因水分蒸發而產生的潛熱損失和過冷卻液 滴被加熱到表面溫度所產生的顯熱損失的影響, 得出 臨界電流計算公式為:

$$
\begin{aligned}
& I_{L J}^{2}=\frac{D}{R}\left[( 2 7 3 . 2 - t ) \left(\pi h+\pi \sigma \varepsilon t^{3}\right.\right. \\
& \left.\left.+2 E V w C_{w}\right)+2 E V W_{e} L_{v}\right]
\end{aligned}
$$

其中 V 為風速; $\mathrm{h}$ 為對流換熱係數, 與環境溫度、 
雷諾數和導線外徑有關; $\mathrm{E}$ 為液滴總體收集係數, 與 風速、導線外徑和液滴直徑有關; $\mathrm{C}_{\mathrm{w}}$ 為水的比定壓熱 容, 可取 $4.18 \mathrm{kj} / \mathrm{kg} . \mathrm{K} ; \mathrm{L}_{\mathrm{v}}$ 為水的汽化潛熱, 可取 $2260 \mathrm{kj} / \mathrm{kg} ; \mathrm{W}_{\mathrm{e}}$ 為導線表面蒸發的液體水分, 為:

$$
W_{E}=0.622 \pi h \frac{P_{273.2}-P_{t}}{2 E V P C_{a}}
$$

其中 $\mathrm{P}$ 為氣壓； $\mathrm{P}_{\mathrm{t}}$ 為濕空氣溫度 $\mathrm{t}$ 時的飽和蒸汽 壓，可由 Goff-Gratch 公式求得; $\mathrm{C}_{\mathrm{a}}$ 為空氣的比定壓 熱容，可取 $1.006 \mathrm{kj} / \mathrm{kg} . \mathrm{K}$ 。

臨界電流值都主要取決於外部氣象條件和導線 本身的特性參數。而導線型號一般不會改變，所以只
要知道覆冰時導線所處的氣象條件, 即可確定臨界電 流值。圖 3 為導線LGJ-120/25、LGJ-210/35、LGJ-300/25 和 LGJ-400/35 在環境溫度為 $268.2 \mathrm{~K}\left(-5^{\circ} \mathrm{C}\right)$ 時的臨界 電流隨風速變化情況。

上述四種導線在風速為 $5 \mathrm{~m} / \mathrm{s}$ 時的臨界電流隨環 境溫度變化的情況如圖 4 所示。

要能求出臨界電流, 應知道輸電線路所在區域的 氣象條件 (氣溫和風速), 目前中國部分輸電線路上 安裝有冰風觀測系統，可以傳回這些資訊，甚至能傳 回導線覆冰狀況的圖片。通過即時獲取這些資料, 計 算出臨界電流，控制變壓器的分接開關，就可以實現 防止導線覆冰的目的。

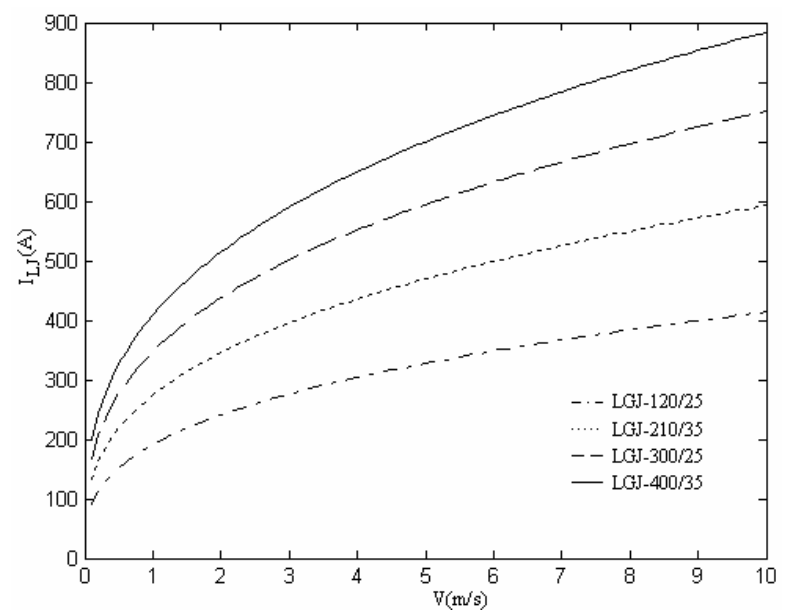

圖 3. 臨界電流與風速的關係圖

Figure 3. The relation between critical-currents and wind-speeds

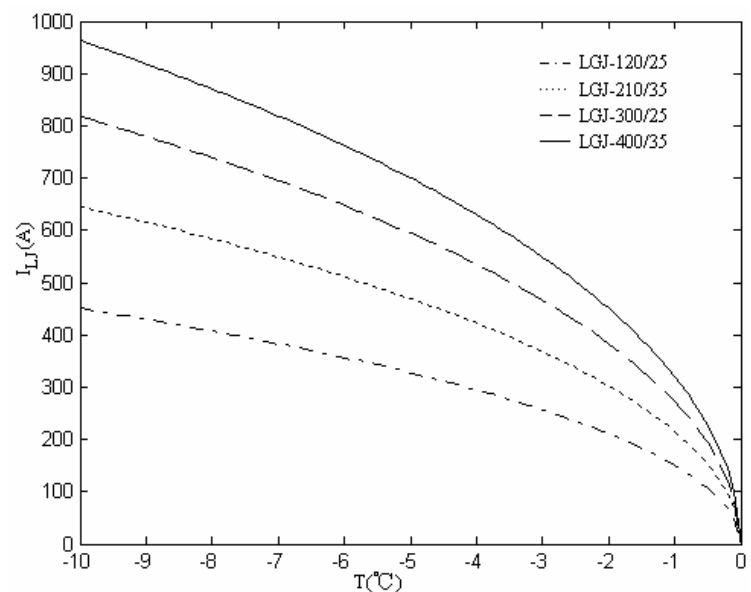

圖 4. 臨界電流與環境溫度的關係圖

Figure 4. The relation between critical-currents and environment-temperature 


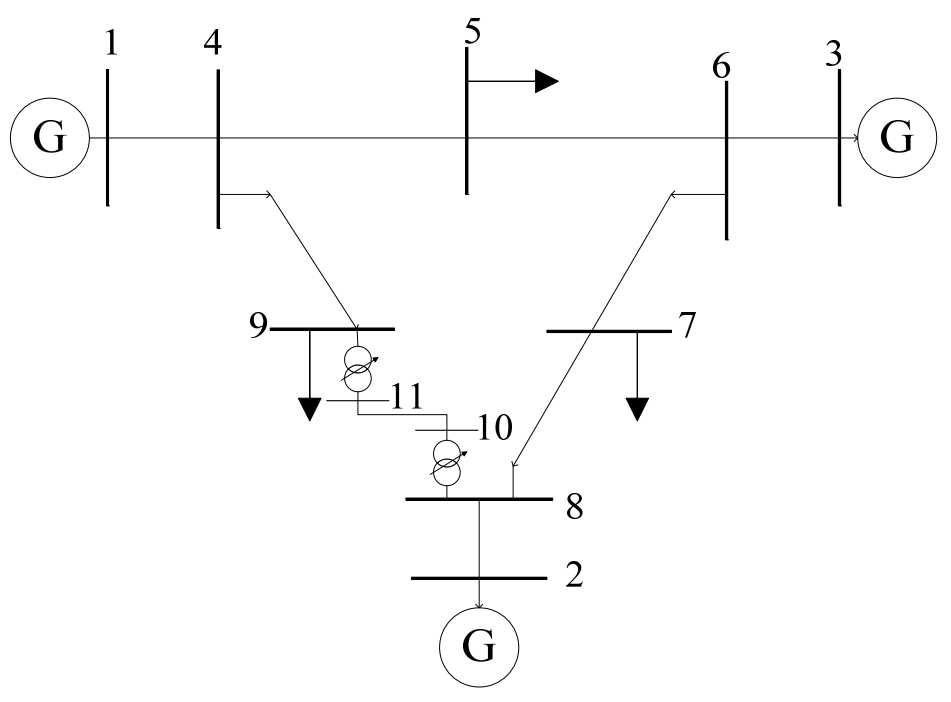

圖 5. 仿真系統電路圖

Figure 5. Circuit of simulating system

\section{4 仿 真}

為了驗證上述結論的正確性，採用 IEEE9 節點的 模型來進行仿真, 如圖 5 所示。設在惡劣的氣象條件 下, 編號為 8 和 9 的母線之間的線路需要增加電流防 覆冰, 線路基準容量為 100MVA, 基準電壓為 $230 \mathrm{kV}$, 導線型號為 LGJ-240/30。防覆冰變壓器没有投入之 前, 經潮流計算可知, 母線 8 和 9 的電壓分別為 $0.996 \angle 3.8^{0} 、 0.958 \angle-4.35^{\circ}$ ，線路流過的潮流為 $84.04+j 14.28 M V A$ ，線路上流過的電流為 $381.6 \mathrm{~A}$ 。

如果冰風觀測系統傳回的氣象條件為環境溫度 $-5^{\circ} \mathrm{C}$, 風速 $5 \mathrm{~m} / \mathrm{s}$, 那麼按公式 (13) 可計算出防覆冰 臨界電流為 $514 \mathrm{~A} 。$ 防覆冰電流遠大於線路運行電流, 這麼大的電流通過調節電網的潮流分佈是很難實現 的。現採用調線路兩側的防覆冰變壓器來實現線路電 流增大到臨界電流之上。

按公式 (1) ( 7), 並設變壓器相鄰分接開關 之間繞組對應電壓為 $5 \% \mathrm{U}_{\mathrm{N}}$, 可求出 $\mathrm{k}_{8} 、 \mathrm{k}_{9}$ 分別為 1.3 和 1.65 , 導線電流為 $524.45 \mathrm{~A}$ 。導線的線損由調壓前 的 $2.47+j 12.4 M V A$ 變成了 $4.66+j 23.43 M V A$ 。調壓前 後各個節點的電壓變化情沉如表 1 所示，表中節點 1 $\sim 9$ 的電壓都在没有越限。表 2 列出的是調壓前後發 電機發的功率變化情況, 因線損而增加的有功全部由 與母線 1 相連的發電機承擔; 而 3 台發電機發出的無 功都有較大的增加。由於防覆冰線路的無功損耗也有
較大增加, 所以如果母線 8 處能投入無功補償設備, 可大幅減少發電機的無功輸出。

按公式(8)作線路傳輸功率極限校驗, 有

$$
\begin{aligned}
& P_{\max }=\frac{V_{A}^{\prime} V_{B}^{\prime}}{X_{L}} S_{\text {base }}=\frac{0.74 \times 0.602}{0.161} \times 100 \\
& =276.7 \mathrm{MW}
\end{aligned}
$$

表 1 調壓前後節點電壓變化表（p.u.）

Table 1. The changes of node voltage before and after regulator (p.u.)

\begin{tabular}{ccc}
\hline 節點編號 & 調壓前電壓 & 調壓後電壓 \\
\hline 1 & 1.000 & 1.000 \\
2 & 1.000 & 1.000 \\
3 & 1.000 & 1.000 \\
4 & 0.987 & 0.994 \\
5 & 0.975 & 0.977 \\
6 & 1.003 & 0.998 \\
7 & 0.986 & 0.967 \\
8 & 0.996 & 0.97 \\
9 & 0.958 & 0.983 \\
10 & & 0.74 \\
11 & & 0.602 \\
\hline
\end{tabular}

表 2 調壓前後發電機功率變化表 (MVA)

Table 2. The changes of generators power before and after regulator (MVA)

\begin{tabular}{ccc}
\hline 相連節點 & 調壓前 & 調壓後 \\
\hline 1 & $71.95+\mathrm{j} 24.07$ & $75.37+\mathrm{j} 11.37$ \\
2 & $163.00+\mathrm{j} 14.46$ & $163.00+\mathrm{j} 56.58$ \\
3 & $85.00-\mathrm{j} 3.65$ & $85.00+\mathrm{j} 5.55$ \\
\hline
\end{tabular}


而線路傳輸的有功功率為 $69.6 \mathrm{MW}$, 小於傳輸極 限, 所以線路是穩定的。

如果採用有載調壓方式, 則兩側變壓器相互配 合, 輪流進行有載調壓。由於每次調壓繞組數為 5\% 的額定繞組, 對負載的影響很小。調壓過程中, 母線 10 和 11 的電壓逐漸減小, 而線路電流逐漸增加, 其 餘各母線電壓變化很小, 負載的電流電壓變化也很 小，因此調壓過程對用戶的影響小。

\section{5 結 論}

本文提出了輸電線路降壓運行防覆冰的控制策 略, 通過安裝在輸電線路兩端的防覆冰變壓器調壓, 增加線路電流, 從而使線路發熱增加, 防止線路覆 冰, 保證輸電線路的安全運行。採用這種預防性措 施, 使輸電線路在惡劣的氣象條件下能夠正常工作。 防覆冰變壓器如採用有載調壓, 可實現帶負荷調壓, 對用戶不產生影響。如果能與無功補償設備配合, 將 對電網的影響更小，調壓效果更好。

\section{致謝}

本文的研究成果在中國國家電網公司資助下取 得。

\section{REFERENCES}

[1] LI Zai-hua, BAI Xiao-min, and ZHOU Zi-guan, "Preven- tion and treatment methods of ice coating in power networks and its recent study," Power System Technology, China, Vol. 32, pp. 7-13, April 2008.

[2] CHANG Hao, SHI Yan, and YIN Wei-yang, "Ice-melting technologies for HVAC and HVDC transmission line," Power System Technology, China, Vol. 32, pp. 1-6, May 2008.

[3] FARZENEHM, "Ice accretion on high-voltage conductors and insulators and related phenomena," Philosophical Transactions of the Royal Society, Vol. 10, pp. 2971-3005, 2000.

[4] YAO Yu-bin, WU Zhi-liang, and WANG Dan, "Study on transformer representation in power system," Relay, China, Vol. 35, pp. 16-20, 2007.

[5] HAN Fang, XU Qing-song, and HOU Wei, “Application of overhead transmission line dynamic ampacity calculation method," Electric Power Construction, China, Vol. 29, pp. 39-43, January, 2008.

[6] LIU He-yun, ZHOU Di, and FU Jun-pin, "Heat transfer investigation on critical current to prevent wires from icing," Electric Power, China, Vol. 34, pp. 42-44, April 2001.

[7] Maurice Huneault, Christian Langheit, and Josee Caron, "Combined models for glaze ice accretion and de-icing of current-carrying electrical conductors," Transactions on Power Delivery, Vol. 20, No. 2, pp. 1611-1616, 2005.

[8] Hyde M. Merrill and James W. Feltes, "Transmission icing: A physical risk with a physical hedge," IEEE PES General Meeting, Montreal, pp. 1-7, June 2006. 